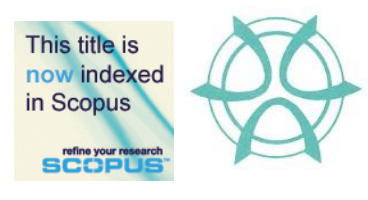

PLANNING MALAYSIA:

Journal of the Malaysian Institute of Planners

VOLUME 16 ISSUE 2 (2018), Page 293 - 303

\title{
INHALABLE AND RESPIRABLE DUST CONCENTRATION OF SOILED STONE, METAL AND CERAMIC ARTEFACT INSIDE NATIONAL MUSEUM MALAYSIA
}

\author{
Shamzani Affendy Mohd Din 1 , Nur Baiti Mat Husin ${ }^{2}$ \& Rashidi Othman ${ }^{3}$ \\ ${ }^{1,2,3}$ Kulliyyah of Architecture and Environmental Design \\ INTERNATIONAL ISLAMIC UNIVERSITY MALAYSIA
}

\begin{abstract}
Airborne particulate matter is a key indicator of air pollution brought into the air by a variety of natural and human activities. As it can travel in distances and suspended in the atmosphere, it affects human health and museum artefact. The primary idea of this paper is to discuss the mass concentration of airborne particulates matter in terms of inhalable and respirable dust from the stone, metal and ceramic display showcase. The fluctuation of temperature and relative humidity, the museum cleaning activity, the usage of HVAC system and construction activity affect the soiling defect of stone, metal and ceramic artefact. The approach selected to collect primary data for this research is by conducting case study at the National Museum of Malaysia. Personal air sampling was conducted using Casella 7-Holes and Cyclone sampler head. Results revealed high abundances of inhalable dust at stone and ceramic artefact both in Galley A and B. This study is beneficial towards the Jabatan Muzium Malaysia (JMM), Department of Environment (DOE), Ministry of Health (MOH) and Ministry of Natural Resources and Environment (MONRE) by emphasising that reducing air pollution will reduce soiling defect of the museum artefact. Thus, it can reduce government expenses to the museum management towards cleaning procedure for the damaged artefact.
\end{abstract}

Keyword: airborne particulates matter, soiling defects, inhalable dust, respirable dust, artefact 
Shamzani Affendy Mohd Din, Nur Baiti Mat Husin \& Rashidi Othman

Inhalable and Respirable Dust Concentration of Soiled Stone, Metal and Ceramic Artefact Inside National Museum Malaysia

\section{INTRODUCTION}

The conservation of museum artefact is influenced by the indoor environment of the museum such as the museum microclimate and air pollutants. Temperature and relative humidity $(\mathrm{RH})$ variations, metabolic actions and excretions of microorganism and gaseous and particulate pollution all play an important role in the deteriorations of the artefact (Camuffo et al., 2001; Gysels et al., 2004; Hu et al., 2015). So, the temperature, humidity, particulate matter and gaseous buffering determine the microclimate of the museum.

The fluctuation of temperature and relative humidity increases the dust deposition inside the museum gallery and onto the artefact surfaces. As cited by Tzanis et al. (2011) and Hu et al. (2015), the effect of dust deposition towards artefact is called soiling defects or surface blackening. After certain period of time, the deposited dust or airborne particulates will alter the surface of artefact and reduce the cultural and heritage value of the artefact.

Through literature exploration, majority of investigations on the characterization of airborne particulates matter deposited onto the surface of the museum building and museum collections were from United States, Europe, Middle East, and Asian countries such as Japan, China and Malaysia. In Malaysia, there have been similar studies which investigate the heavy metal contained in respirable and inhalable dust in the National Textiles Museum and National Museum of Malaysia.

The researchers have stressed on the scope of heavy metal concentration in the museum showcase, indoor and outdoor. Thus, detail characterization of airborne particulates matter collected from stone, metal and ceramic artefact at three different types of environment such as outdoor, indoor and inside display showcase was analysed. The study is further argued in the differences found in between working day and holiday.

The primary idea of this research is to investigate the existence of heavy metal concentration inside airborne particulates matter which expose the inorganic artefact towards soiling defects. The objectives of conducting this research are (i) to identify the sources of airborne particulates matter affecting the artefact deterioration in the National Museum Malaysia, (ii) to measure the mass concentration of airborne particulates matter in the National Museum Malaysia, (iii) to analyse the contents and composition of heavy metal from the airborne particulates matter in the National Museum Malaysia and (iv) finally to propose the methods of reducing artefact deterioration in the museum.

This paper will only discuss on the matter pertaining to the mass concentration of airborne particulates matter in terms of inhalable and respirable dust from the stone, metal and ceramic display showcase. 
PLANNING MALAYSIA

Journal of the Malaysia Institute of Planners (2018)

\section{LITERATURE REVIEW}

Airborne particulates matter suspended in the atmosphere are known as dust, dirt, soot, smoke and liquid droplets. Museum artefact that are exposed to airborne particulates matter come from various indoor sources. The sources includes the use of HVAC system (Camuffo et al., 2001; Fu \& Li, 2006), cleaning services (Afshari, Matson, \& Ekberg, 2005; Guo et al., 2010), vacuuming process (Afshari et al., 2005), particulates from displayed artefact or storage room (Abdel-Kareem, 2010; Nazaroff, 2002), open entrance (Blondeau, Iordache, Poupard, Genin, \& Allard, 2005; Anaf et al., 2012), particulates from outside and from visitors (Horemans, Schalm, De Wael, Cardell, \& Grieken, 2012; Hu et al., 2011) and occupants in the museums (Hospodsky et al., 2012; Saraga, Pateraki, Papadopoulos, Vasilakos, \& Maggos, 2011).

From all the sources mentioned above, the airborne particulates matter will be suspended inside the museum gallery and deposited onto the artefact either vertically or horizontally due to gravitational forces. The airborne will be deposited on the display boxes, display textile frames, gallery floors, painting, sculpture and exposed artefact. After some time, the soiling defects can be seen clearly, for instance through blackening of the surface or brownish spots on paper. Therefore it is supported that airborne particulates matter significantly affects the soiling of the artefact.

Airborne particulates matter in the atmosphere significantly affects global climate (Fisk, 2015), human health (Adar, Filigrana, Clements, \& Peel, 2014; Kim, Kabir, \& Kabir, 2015), flora and fauna as well as building materials (Watt, Jarett, \& Hamilton, 2008 \& Tzanis et al., 2011). The airborne particulates matter in the air is distributing in all types of ecosystems from desert to oceans by cooling and heating the atmosphere. Large cities with higher traffic and poor air pollutant dispersion are more susceptible to negative health effects due to airborne particulates matter.

Moreover, high traffic density in urban areas has higher $\mathrm{PM}_{25}$ levels compared to the suburban background area. Hence, transportation sector in big cities plays important roles in the distribution of pollutants to the atmosphere. Due to the heavy traffic density and rapid urban development, global warming and climate change occur.

Airborne particulates originate from various manmade and natural sources such as car exhaust, power plants, forest fires, evaporation from petroleum products, agriculture, natural living plants, dust storms, breaking ocean waves, volcanoes (NASA Ames Research Center, 2007). The airborne particulates in terms of haze particles suspended in the atmosphere, affect the climate by changing the flow of radiant energy from the sun to the Earth's surfaces and within the atmosphere. Airborne particulates directly, scatter and absorb solar radiation while indirectly changing cloud properties, rain, snow, and atmospheric mixing. 
Shamzani Affendy Mohd Din, Nur Baiti Mat Husin \& Rashidi Othman

Inhalable and Respirable Dust Concentration of Soiled Stone, Metal and Ceramic Artefact Inside National Museum Malaysia

The outdoor pollutants will enter the building through various sources such as street dust, motor vehicle exhaust, and buildings heating facilities or human activity. Then, the airborne particulates matter will disperse and deposit into the building to become dust. As explained by Yoon and Brimblecombe (2001), the deposited dust can detract and soils museum artefact, furniture and fittings appearance. Furthermore, dust that deposits inside the building can transport harmful chemical substances to the surface of museum collections.

\section{METHODOLOGY}

The sampling location for the research is National Museum Malaysia. The museum is chosen because it is located in the city centre of Kuala Lumpur and 50 meters from the museum south entrance have an ongoing construction of Mass Rapid Transport (MRT) and also Jalan Damansara. Besides, 100 meters from the museum north entrance is facing the congested highway named Jalan Damansara. Hence, it is proven that the museum is critically exposed towards transportation and construction particles pollutants.

This research studies the soiling defect of inorganic artefact which includes stone, metal and ceramic. Based on previous research, dust deposition or soiling defect on inorganic artefact are more visible and crucial compared to organic artefact. Gallery A and Gallery B of National Museum Malaysia are likely to have most of the 3 types of inorganic artefact. The location and name of each artefact inside the National Museum Malaysia can be referred in Table 1.

After determining the case study, personal sampling method was conducted. In order to represent the inhalable and respirable dust, Casella 7-Holes and Cyclone sampler head were used to measure the individual personal exposure towards airborne particulates. The sampling was conducted for 8 hours during museum office hour which is from 9 a.m. to 6 p.m. The research collected an overall sixty-four (64) samples. There were sixteen (16) sampling points during weekdays and weekends respectively. Thirty-two (32) samples alone were collected for 7-Holes sampler head along with thirty-two samples (32) from Cyclone sampler head.

Samples were then transported to the Herbarium laboratory to digest the metals from the airborne particulates using Milestone S.r.l. - START D Microwave Digestion System. Next, samples were replicated into three (3) sections to conduct elemental analysis through Perkin Elmer NexION 300X ICPMS. Finally, the results were run through statistical analysis using Statistical Analysis System (SAS) software. The analysis involved two-way analysis of variance (ANOVA) test. The analysis was done to observe the metal interaction with different museum location, time of exposure, type of sampling head and metal concentration. 
PLANNING MALAYSIA

Journal of the Malaysia Institute of Planners (2018)

Table 1: The location of the soiled stone, metal and ceramic artefact inside Gallery A and B of the National Museum Malaysia.

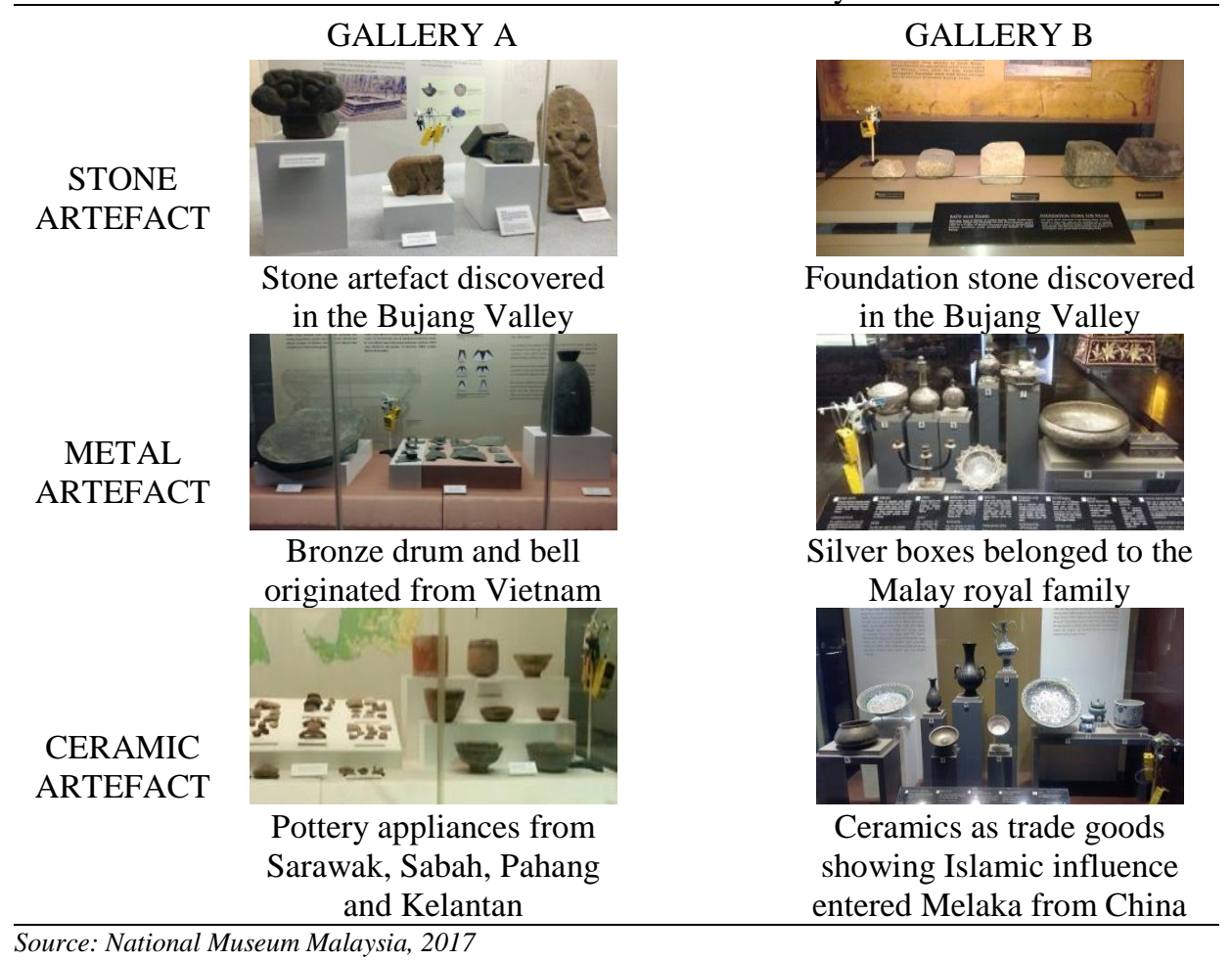

\begin{abstract}
ANALYSIS AND DISCUSSION
This section discusses the analysis of inhalable and respirable dust concentration in the comparison between weekday and weekend sampling at Gallery A and Gallery B of the National Museum Malaysia. The discussion emphasize on the comparison of the relationship between inhalable and respirable dust concentration. Table 2 below shows the results for mass concentration of inhalable and respirable dust collected from stone, metal and ceramic artefact in comparison to the weekday and weekend sampling exposure. The bar graphs in Figure 1 and Figure 2 are rendered for further discussion regarding the comparison between the two galleries.
\end{abstract}


Shamzani Affendy Mohd Din, Nur Baiti Mat Husin \& Rashidi Othman

Inhalable and Respirable Dust Concentration of Soiled Stone, Metal and Ceramic Artefact Inside National Museum Malaysia

Table 2: The mass concentration of inhalable and respirable dust collected from stone, metal and ceramic artefact

\begin{tabular}{|c|c|c|c|c|c|}
\hline \multirow[b]{2}{*}{$\begin{array}{l}\text { Type of } \\
\text { Gallery }\end{array}$} & \multirow[b]{2}{*}{$\begin{array}{l}\text { Type of } \\
\text { Artefact }\end{array}$} & \multicolumn{2}{|c|}{ Inhalable Dust } & \multicolumn{2}{|c|}{ Respirable Dust } \\
\hline & & Weekday & Weekend & Weekday & Weekend \\
\hline \multirow{3}{*}{ Gallery A } & Stone & 0.660 & 0.104 & 0.095 & 0.063 \\
\hline & Metal & 0.035 & 0.104 & 0.063 & 0.126 \\
\hline & Ceramic & 0.347 & 0.104 & 0.253 & 0.316 \\
\hline \multirow{3}{*}{ Gallery B } & Stone & 0.139 & 0.208 & 0.032 & 0.158 \\
\hline & Metal & 0.069 & 0.035 & 0.063 & 0.063 \\
\hline & Ceramic & 0.069 & 0.174 & 0.032 & 0.284 \\
\hline
\end{tabular}

Figure 1 below shows that the weekday mass concentration of Gallery A stone $\left(0.660 \mathrm{mg} / \mathrm{m}^{3}\right)$ and ceramic artefact $\left(0.347 \mathrm{mg} / \mathrm{m}^{3}\right)$ display showcases was the highest when compared with the other 6 artefact in Gallery A and Gallery B. However, their mass concentration in the weekend was not exceeding the average DOSH standard. In comparison with the artefact from Gallery B, the mass concentration from weekends sampling is considerably high at both stone and ceramic display showcases with the value of $0.208 \mathrm{mg} / \mathrm{m}^{3}$ and $0.174 \mathrm{mg} / \mathrm{m}$ consecutively.

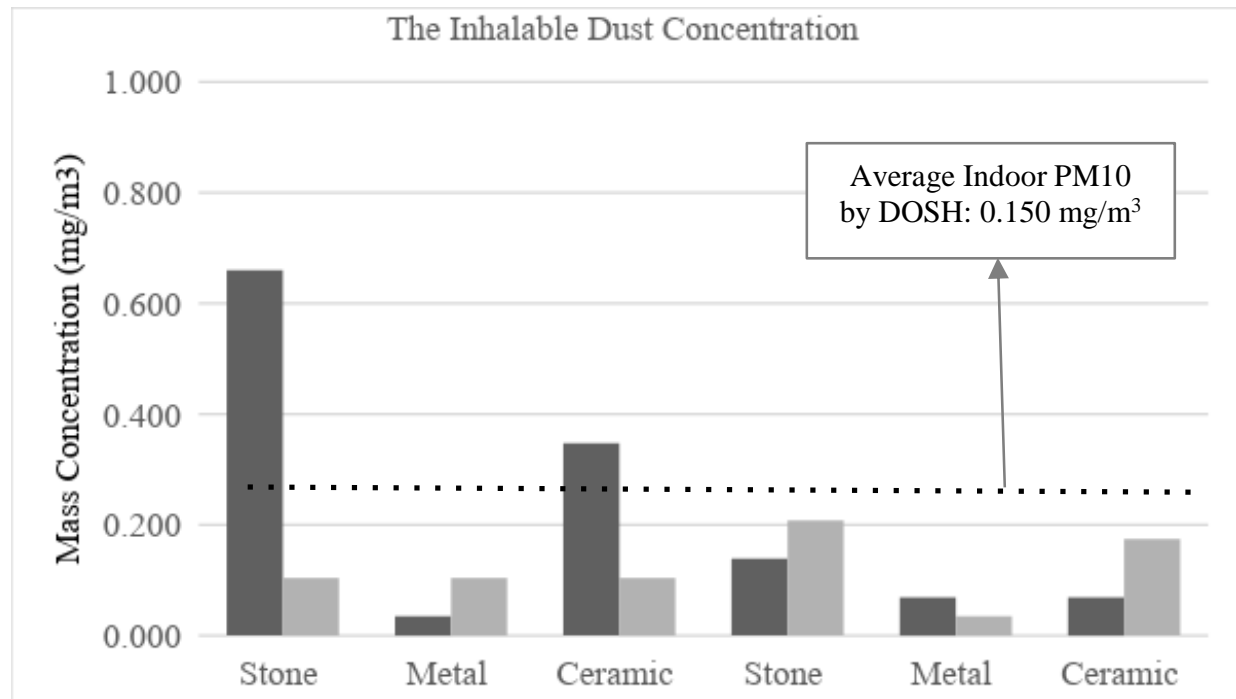

Figure 1: Comparison of inhalable dust concentration between weekday and weekend sampling from display showcase in Gallery A and B. 
PLANNING MALAYSIA

Journal of the Malaysia Institute of Planners (2018)

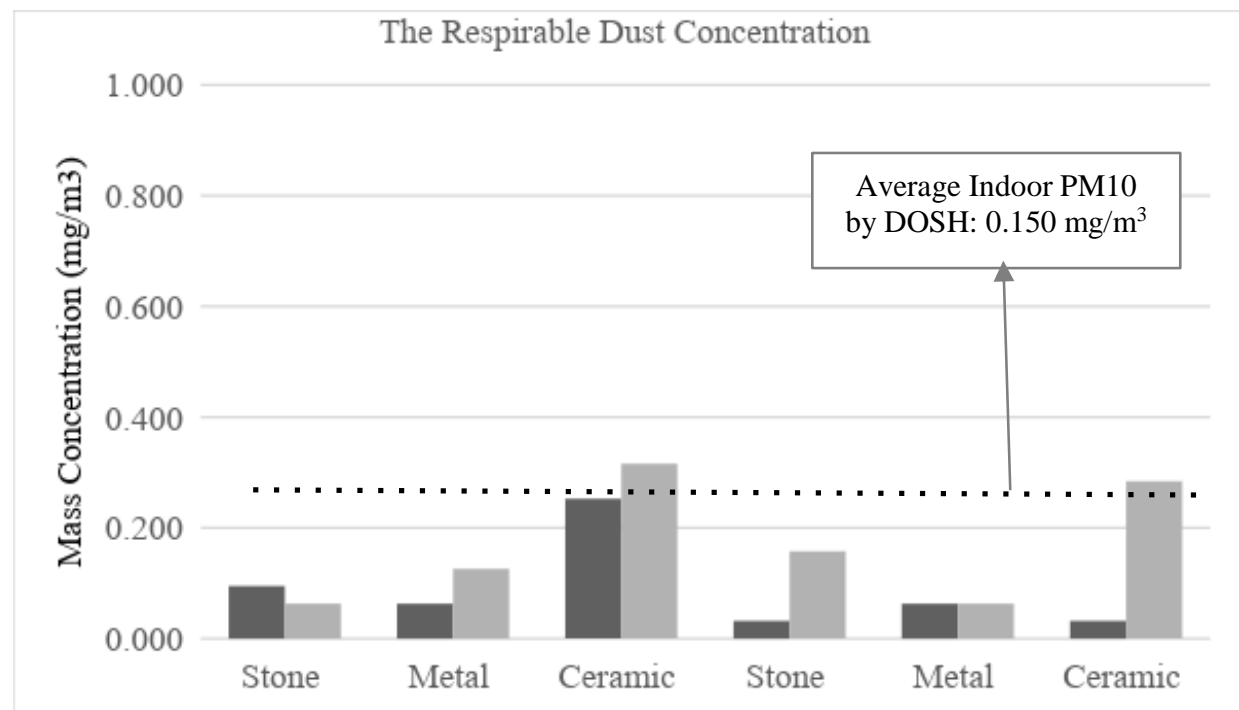

Figure 2: Comparison of respirable dust concentration between weekday and weekend sampling from display showcase in Gallery A and B.

From the above results, the weekday dust concentrations at the stone and ceramic artefact are the highest due to the location of the display showcase. The stone display showcase at Gallery A was located 18 meters near to the gallery entrance while at Gallery B, 15 meters away from the gallery entrance. Hence, particles pollution from outdoor sources that suspended in air enter Gallery A and $\mathrm{B}$ and deposited more at stone and ceramic artefact.

Besides, Gallery A and Gallery B were situated on the ground floor as well as attached to the museum lobby where many tourists gather hence there would be a lot of air exchange (Hu et al., 2011). In addition, the number of tourists coming into the museum during the weekday are more than the weekend. Moreover, the north entrance of the museum was facing the MRT construction and Jalan Damansara. The particle pollutants from construction and transportation penetrated into the museum lobby through doors and windows gap (Angell, 2005; Charlesworth, Everett, McCarthy, Ordóñez, \& de Miguel 2003).

Furthermore, the high concentration of airborne at stone and ceramic artefact was due to the various indoor sources. The significant source was the existent particulates released from the archaeological artefact itself (Grossi, Esbert, Diaz-Pache, \& Alonso, 2003). Besides, the cleaning activities which was done every morning used chemical solution which affected the dust deposition in the display showcase (Guo et al., 2010).

From the graph in Figure 1 and 2, it was clear that airborne particulates collected in metal artefact display showcase from Gallery A and B had the lowest concentration. The display showcase was 43 meters far away from the gallery 
Shamzani Affendy Mohd Din, Nur Baiti Mat Husin \& Rashidi Othman

Inhalable and Respirable Dust Concentration of Soiled Stone, Metal and Ceramic Artefact Inside National Museum Malaysia

entrance. So, fewer particles were deposited inside the display showcase. The findings showed that metal artefact exhibited in Gallery A and Gallery B were not prone to dust deposition. Metal artefact had more tendencies to corrosion (Schiavon, Celauro, Manso, Brunetti, \& Susanna, 2013; Tzanis et al., 2011). As can be seen from the stone and ceramic artefact in Figure 3 and 4 below, soiling defects were more visible at the stone and ceramic artefact in the Gallery A and Gallery B.

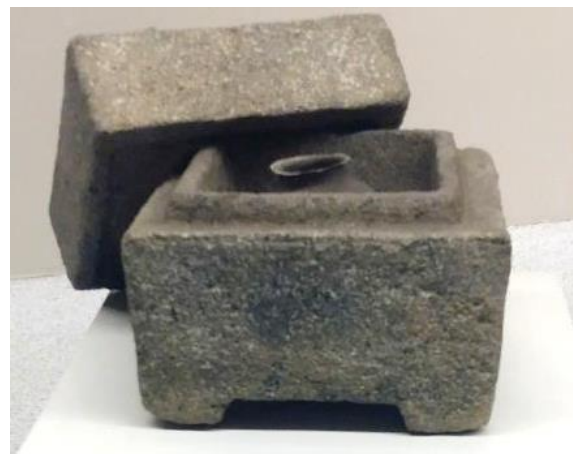

Figure 3: Stone artefact discovered in the Bujang Valley

Source: National Museum Malaysia, 2017

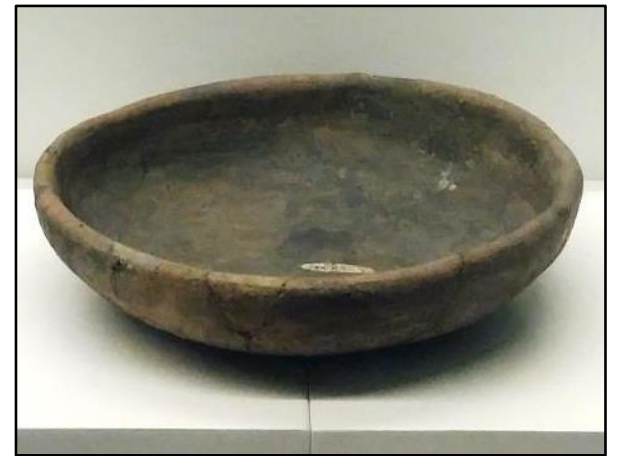

Figure 4: Pottery appliances from Kelantan

Source: National Museum Malaysia, 2017

When comparing the overall dust concentration between total inhalable dust and respirable dust as in Figure 1 and 2 above, the analysis indicated that the fraction of airborne particulates entered the nose and mouth and deposited into the respiratory tract of museum visitors was significantly higher than the fraction of airborne particulates that penetrated into the human lung. Particles that deposited either in the respiratory tract or in the lung and remained for a long time increased the potential of diseases to the museum visitors.

Such diseases could be heart or lung disease, nonfatal heart attacks, irregular heartbeat, aggravated asthma, decreased lung function, and increased respiratory symptoms such as irritation of the airways, coughing, or difficulty breathing (Kim et al., 2015). As described by Shamzani Affendy and Pooley (2016), the size of respirable dust is defined by their ability to gain access to the human lung. Thus, the dust exposure will bring harm towards the health of museum visitors and the artefact, even though the concentration of respirable dust is found lower than inhalable dust. Dust deposition at stone and ceramic artefact will cause an irreversible damage and loss of culture and social value. 
PLANNING MALAYSIA

Journal of the Malaysia Institute of Planners (2018)

\section{CONCLUSION}

In conclusion, the objective of research which is to determine the mass concentration of airborne particulates soiling defect is achieved. The mass concentration of total inhalable dust at Gallery A and Gallery B were significantly higher than respirable dust. The exposure of airborne particulates was seen critically at stone and ceramic artefact due to both outdoor and indoor sources. However, metal artefact was less affected to soiling defect because the material is prone towards corrosion. The high concentration of inhalable dust and respirable dust cause harm towards artefact in terms of soiling as well as harmful to the museum visitors' health.

The results from this study stressed the importance of controlling and reducing outdoor and indoor pollution in relation to artefact conservation and preservation by the specialist and management of the Jabatan Muzium Malaysia (JMM). This study is beneficial to the Department of Environment (DOE), Ministry of Health (MOH) and Ministry of Natural Resources and Environment (MONRE) through emphasizing that reducing air pollution will reduce soiling rates of museum artefact. Thus, it can reduce government expenses on cleaning procedure of the damaged artefact. If soiling can be prevented, future generation can also gain benefit in learning about the historical heritage of Malaysia.

\section{ACKNOWLEDGEMENT}

The authors would like to acknowledge the Ministry of Higher Education (MOHE) for providing grant RIGS16-394-0558 and IIUM Research Management Centre for facility support to make this research possible.

\section{REFERENCES}

Abdel-Kareem, O. (2010). Monitoring, controlling and prevention of the fungal deterioration of textile artifacts in the museum of Jordanian heritage. Mediterranean Archaeology and Archaeometry, 10(2), 85-96.

Adar, S. D., Filigrana, P. A., Clements, N., \& Peel, J. L. (2014). Ambient coarse particulate matter and human health: A systematic review and meta-analysis. Current Environmental Health Reports, 1(3), 258-274.

Afshari, A., Matson, U., \& Ekberg, L. E. (2005). Characterization of indoor sources of fine and ultrafine particles: a study conducted in a full-scale chamber. Indoor Air, 15(2), 141-50.

Anaf, W., Horemans, B., Madeira, T. I., Carvalho, M. L., Wael, K. De, \& Grieken, R. Van. (2012). Effects of a constructional intervention on airborne and deposited particulate matter in the Portuguese National Tile Museum, Lisbon. Environmental Science and Pollution Research, 20(3), 1849-1857.

Angell, W. (2005). Construction and indoor airborne contaminants. InformeDesign, 3(7), 
Shamzani Affendy Mohd Din, Nur Baiti Mat Husin \& Rashidi Othman

Inhalable and Respirable Dust Concentration of Soiled Stone, Metal and Ceramic Artefact Inside National Museum Malaysia

$1-4$.

Blondeau, P., Iordache, V., Poupard, O., Genin, D., \& Allard, F. (2005). Relationship between outdoor and indoor air quality in eight French schools. Indoor Air, 15(1), $2-12$.

Camuffo, D., Van Grieken, R., Busse, H.-J., Sturaro, G., Valentino, A., Bernardi, A., ...\& Ulrych, U. (2001). Environmental monitoring in four European museums. Atmospheric Environment, 35(1), 127-140.

Charlesworth, S., Everett, M., McCarthy, R., Ordóñez, A., \& de Miguel, E. (2003). A comparative study of heavy metal concentration and distribution in deposited street dusts in a large and a small urban area: Birmingham and Coventry, West Midlands, UK. Environment International, 29(5), 563-573.

Fisk, W. J. (2015). Review of Some Effects of Climate Change on Indoor Environmental Quality and Health and Associated No-Regrets Mitigation Measures. Building and Environment, 86, 70-80.

Fu, Z., \& Li, N. (2006). Airborne particulate matter in HVAC systems and its influence on indoor air quality. Energy Systems Laboratory, Texas A\&M University. Retrieved from http://hdl.handle.net/1969.1/5270

Grossi, C. M., Esbert, R. M., Diaz-Pache, F., \& Alonso, F. J. (2003). Soiling of building stones in urban environments. Building and Environment, 38(1), 147-159.

Guo, H., Morawska, L., He, C., Zhang, Y. L., Ayoko, G., \& Cao, M. (2010). Characterization of particle number concentrations and PM2.5 in a school: Influence of outdoor air pollution on indoor air. Environmental Science and Pollution Research International, 17(6), 1268-1278.

Gysels, K., Delalieux, F., Deutsch, F., Van Grieken, R., Camuffo, D., Bernardi, A., ...\& Wieser, M. (2004). Indoor environment and conservation in the Royal Museum of Fine Arts, Antwerp, Belgium. Journal of Cultural Heritage, 5(2), 221-230.

Horemans, B., Schalm, O., De Wael, K., Cardell, C., \& Grieken, R. Van. (2012) Atmospheric composition and micro-climate in the Alhambra monument, Granada (Spain), in the context of preventive conservation. IOP Conference Series: Materials Science and Engineering, 37, 12002.

Hospodsky, D., Qian, J., Nazaroff, W. W., Yamamoto, N., Bibby, K., Rismani-Yazdi, H., \& Peccia, J. (2012). Human occupancy as a source of indoor airborne bacteria. PloS One, 7(4), e34867.

Hu, T., Cao, J., Ho, K., An, Z., Lee, S., Chow, J. C., ...\& Li, H. (2011). Winter and summer characteristics of airborne particles inside Emperor Qin's Terra-Cotta Museum, China: A study by scanning electron microscopy-energy dispersive x-ray spectrometry. Journal of the Air \& Waste Management Association, 61(9), 914922.

Hu, T., Jia, W., Cao, J., Huang, R., Li, H., Liu, S., ...\& Zhu, Y. (2015). Indoor air quality at five site museums of Yangtze River civilization. Atmospheric Environment, 
123(Part B), 449-454.

Kim, K., Kabir, E., \& Kabir, S. (2015). A review on the human health impact of airborne particulate matter. Environment International, 74, 136-143.

NASA Ames Research Center. (2007). NASA studies how airborne particles affect climate change. Retrieved July 24, 2017, from www.sciencedaily.com

Nazaroff, W. (2002). Indoor particulate matter of outdoor origin : Importance of sizedependent removal mechanisms. Environmental Science and Technology, 36(2), 200-207.

Saraga, D., Pateraki, S., Papadopoulos, A., Vasilakos, C., \& Maggos, T. (2011). Studying the indoor air quality in three non-residential environments of different use: A museum, a printery industry and an office. Building and Environment, 46(11), 2333-2341.

Schiavon, N., Celauro, A., Manso, M., Brunetti, A., \& Susanna, F. (2013). Iron-Age bronze statuettes in Southern Portugal: Combining archaeological data with EDXRF and BSEM + EDS to assess provenance and production technology. Applied Physics A: Materials Science and Processing, 113(4), 865-875.

Shamzani Affendy, M. D., \& Pooley, F. D. (2016, August). Comparison of the physical characteristics of airborne and inhaled coal dust samples. Environmental Conservation, Clean Water, Air \& Soil (CleanWAS). August 26-28, 2016, China.

Tzanis, C., Varotsos, C., Christodoulakis, J., Tidblad, J., Ferm, M., Ionescu, a., ...\& Kreislova, K. (2011). On the corrosion and soiling effects on materials by air pollution in Athens, Greece. Atmospheric Chemistry and Physics, 11(23), 1203912048.

Watt, J., Jarrett, D., \& Hamilton, R. (2008). Dose - response functions for the soiling of heritage materials due to air pollution exposure. Science of the Total Environment, 400(1-3), 415-424.

Yoon, Y. H., \& Brimblecombe, P. (2001). The distribution of soiling by coarse particulate matter in the museum environment. Indoor Air, 11(4), 232-240. 